\title{
The Effects of Mating Cues and Intrasexual Competition on Humor Production
}

\author{
Efrat Barel \\ Department of Behavioral Sciences, The Max Stern Academic College of Emek Yezreel, Emek Yezreel, Israel \\ Email: efratb@yvc.ac.il
}

How to cite this paper: Barel, E. (2019). The Effects of Mating Cues and Intrasexual Competition on Humor Production. Psychology, 10, 320-335.

https://doi.org/10.4236/psych.2019.103023

Received: January 14, 2019

Accepted: February 18, 2019

Published: February 21, 2019

Copyright () 2019 by author(s) and Scientific Research Publishing Inc. This work is licensed under the Creative Commons Attribution International License (CC BY 4.0).

http://creativecommons.org/licenses/by/4.0/

\begin{abstract}
The roles of mating cues and of intrasexual competition in humor production have not yet been assessed. Therefore, the present study explored the influence of implicit mating cues on humor enhancement. In two experiments involving 306 participants, using a priming methodology to examine sex differences and enhancement in humor production ability, participants were exposed to unattractive and attractive opposite-sex photographs, after which their humor production ability was rated. Studies differed in presentation durations of primes, and manipulation of intrasexual competition. The findings of Study 2 showed that, under conditions of intrasexual competition, men were superior to women in humor production ability and exhibited enhancement in humor ability following exposure to attractive women primes. The findings broaden the evolutionary cognitive framework in relation to sexual selection, differential parental investment, and social cognition.
\end{abstract}

\section{Keywords}

Sex Differences, Sexual Selection, Humor Production, Intrasexual Competition, Priming, Mating Cues

\section{Introduction}

Is it possible to alter or enhance one's capabilities or attributes when exposed to implicit cues? And can these attributes be modified to fit preferences of the other sex? A growing body of evidence in evolutionary psychology and social cognition research suggests that mating cues can activate behaviors linked to sex-differentiated mate preferences (Yong \& Li, 2012). To test this premise, I conducted two studies that explored the influence of implicit mating cues on humor enhancement, based on the framework of social cognition and evolutionary psychology. 
Evolutionary psychology research routinely shows sex differentiation in mate preferences based on different fitness pressures (Millar \& Ostlund, 2006). For example, men universally have developed a preference for good looks and health in a mate, whereas women have developed a preference for social status, financial resources, stability, and intelligence (Buss, 1989, 2003; Shackelford, Schmitt, \& Buss, 2005). Among these virtues, intelligence is highly valued by women because of its predictive value for other desired qualities, such as social and economic success, creativity (Miller, 1999; Kanazawa, 2000), artistic virtuosity (Miller, 2001), and good health (Arden, Gottfredson, \& Miller, 2009). Humor production ability has been suggested as a prominent indicator of intelligence, and empirical findings provide support for this notion (e.g., Feingold \& Mazzella, 1991; Greengross \& Miller, 2011; Howrigan \& MacDonald, 2008).

Humor is a universal attribute and has been a part of the human behavioral repertoire for thousands of years. In their review of the evolutionary origins of humor, Polimeni and Reiss (2006) examined theories and studies from various scientific fields (e.g., neurobiology, cognitive archaeology) that supported the suggested adaptive function of humor. They suggested that exposure to a humorous stimulus generates laughter, which in turn induces a positive emotional state that facilitates further social activity. Furthermore, laughter is pleasurable and therefore serves as a reinforceable behavior. Various evolutionary theories have been suggested to explain why humor and laughter could be evolutionarily adaptive. For example, Alexander (1986) proposed that the major benefit provided by telling jokes is the facilitation of social status. Jung (2003) suggested that humor and laughter facilitate social cooperation by transferring information about attributed mental states and signaling to others the willingness for cooperate. Animal models provide further support for the adaptive function of humor. Chimpanzees' response to tickling with laughter-like behavior implies that the origin of laughter and humor can be tracked million years ago back to the common ancestor of Homo sapiens and chimpanzees (Dawkins, 2004). Younger primates display teasing-like behavior in the form of play, which facilitates learning about the social environment and hierarchy (De Waal, 1982). The development of humor in humans also implies that it is evolutionarily adaptive. It begins with spontaneous smiling in infants, which is followed by various forms of play that provoke smile and laughter (peek-a-boo, tickling, chase games). Whereas laughter is considered a reaction to unplanned experiences, humor is thought to be a deliberate performance, and each may at root be different interactional mechanisms with their own respective range of social effects (Reay, 2015). In a broad sense, from a psychosocial perspective, the humor process includes four essential components: a social context; a cognitive-perceptual process; an emotional response; and a vocal-behavior expression of laughter (Martin, 2007). Based on this accumulated evidence, Polimeni and Reiss argued that humor may be the most complex cognitive human function. Its complexity requires a tailored genetic substrate to provide the attributes (e.g., abstract thinking, symbolism, language skills) needed to produce it effectively. 
Humor involves two distinct aspects: the capacity to produce it and the capacity to appreciate it. It has been suggested that the two evolved under the influence of sexual selection (Bressler, Martin, \& Balshine, 2006). Because humor is an indicator of intelligence, women seem to prefer men who have the capacity to produce humor, and likewise men seem to prefer women who have the capacity to be receptive to their humor (Bressler \& Balshine, 2006; Hone, Hurwitz, \& Lieberman, 2015). Empirical findings support this premise. Men showed preference for partners' receptivity of their humor, whereas women, when deciding to go on dates or engage in long-term relationships, valued their partners' production of humor (Bressler et al., 2006; Hone et al., 2015; Lundy, Tan, \& Cunningham, 1998). Miller (2000) argued that no sexual dimorphism in human intelligence is expected because men and women share almost all of the same genes. In contrast, sexual dimorphism is expected in behavioral manifestations of intelligence (for example, art, creativity, humor), because the reproductive benefits of such displays will be higher for men than for women. Parental investment theory provides an explanation for this notion. Because parental investment is crucial for reproductive success (survival of offspring), the nature of parental investment by males and females generates the basic dynamics of sexual selection (Geary, 2000). Sharing the biology of reproduction of many other species results in sexual dimorphism in reproductive strategy with women focusing on parental effort and men on mating effort. In turn, sex differences in parental investment cause women to be more selective about mating, which in turn cause men to strive to display virtues that women value (Trivers, 1972). Recently, an examination of sex differences in a real-time dynamics related to humor processing, using event-related potential recording revealed sex differences in the integration of cognitive and emotional components of humor processing (Chang, $\mathrm{Ku}, \&$ Chen, 2018).

The social cognition literature suggests that psychological processes, such as altering one's perceptions and attitudes to conform to potential mate preferences, are involved in human courtship. Studies have explored the degree to which various cues prime the activation of psychological constructs associated with mate attraction, which in turn produce attitude changes in alignment with the mate preferences of the opposite sex (Roney, 2003). Various research paradigms have been used to investigate this phenomenon. Some studies that directly exposed participants to the preferences of the opposite sex lent support for attitudinal changes (Morier \& Seroy, 1994; Zanna \& Pack, 1975). Other studies exposed male subjects to women directly or through photographs. For example, young men who were exposed to young women reported more favorable attitudes toward women's high-rated preferences (e.g., material wealth, indicators of social status, etc.) than men exposed to older women (Roney, 2003). Roney suggested that the visual stimuli (young women) activated the stored female mate preferences in men.

Another line of research has explored the influence of exposure to realistic 
stimuli (photographs of attractive women) on various attributes and behaviors linked to sex-differentiated mate preferences. For example, Griskevicius, Cialdi$\mathrm{ni}$, and Kenrick (2006) showed that priming men with mating cues (photographs of attractive women) led to an increase in creativity when compared to priming men with neutral cues (e.g., photographs of streets), but no differences were documented between women primed with mating cues and those primed with neutral cues. Men have also been found to exhibit higher levels of risk taking (Baker \& Maner, 2008) and of future discounting (Wilson \& Daly, 2004) after viewing pictures of attractive women as opposed to those of unattractive women.

Uncovering the mechanism by which mating cues influence perception and behavior has been the focus of research in social cognition and evolutionary psychology. Millar and Ostlund (2006) argued that priming techniques are particularly useful in understanding mating behavior, given the premise of the evolutionary framework that such behavior is activated through unconscious processes. The present study aimed to investigate the influence of priming mating cues introduced subliminally or supraliminally on humor production. Specifically, I used priming mating cues to examine enhancement in humor production. Subliminal and supraliminal forms of priming refer to the unconscious versus conscious processing of stimuli. Although the exact consciousness threshold is difficult to determine, any prime presented for less than $100 \mathrm{~ms}$ is considered to be a subliminal prime (Phaf, Wendte, \& Rotteveel, 2005). To uncover the role of unconscious and conscious processing of mating cues and their influence on later behavior, I conducted two studies with different presentation durations of primes (i.e., mating cues).

Another key factor in understanding sex differences in mating-related cognition and behavior is intrasexual competition. Competition between members of one sex for mating is based on Darwin's (1871) insight on sexual selection. Males and females are predicted to compete within their sex by displaying the virtues and resources valued by the other sex (Buss, 1988). In elaborating Darwin's theory, Trivers (1972) suggested that males and females are differentiated in their parental investment strategies, which lead them to engage in different degrees of intrasexual competition. Males engage more frequently in male-male competition over mating opportunities than do females. Evidence from nonhuman species supports this notion (for example, Clutton-Brock \& Vincent, 1991). In humans, because both sexes are involved in child rearing, both men and women are expected to be discriminating in mate preferences. Empirical evidence shows that both men and women engage in intrasexual competition, but differ in the tactics they use in male-male and female-female competition (Buss, 1988; Buss \& Dedden, 1990; Fisher \& Fernández, 2017; Walters \& Crawford, 1994). Whereas men compete for acquisition of resources and status, women compete by enhancing their physical attractiveness and achieving a healthy and youthful appearance (Brewer, 2017; Campbell, 2013). In the second study presented here, I assessed the ability to enhance the production of humor as a func- 
tion of intrasexual competition. I used the presence of other same-sex participants during a timed task to create a situation of rivalry by inducing a state of intrasexual competition. Therefore, the presence of potential rival served as another mating cue. Since the asset evaluated in the present study (humor ability) is associated with the mate preferences of females but not of males, I expected that intrasexual competition, although experienced by both sexes, would be manifested only by men.

In sum, the studies described here examined the role of mating cues on humor enhancement. In the first study men and women were primed with attractive and unattractive opposite-sex pictures, after which they were asked to produce verbal humor. I examined the difference in humor production under the two conditions (attractive vs. unattractive) for each sex using a presentation duration of $30 \mathrm{~ms}$ for the primes. In the second study, I added the variable of intrasexual competition to the experimental setting to test whether the cumulative value of mating cues would elicit larger sex differences in humor production with $100 \mathrm{~ms}$ presentation duration of the prime. I hypothesized that mating cues, including the exposure to an attractive member of the opposite sex, would activate asset-display behavior and stored mate preferences in men, but not in women. I further hypothesized that activating female mate preferences in men in the presence of a potential rival would result in enhancement of humor production.

\section{Study 1-Preliminary Study}

The first experiment was designed to examine sex differences in humor production as a function of exposure to attractive and unattractive pictures of the opposite sex. Men and women were subliminally primed with attractive and unattractive pictures of the opposite sex and then asked to provide a funny caption to a given picture; the humorousness of the caption was then analyzed. The hypotheses of Study 1 were as follows:

1) Men will exhibit higher humor production than women.

The main hypothesis was:

2) Men will show greater humor enhancement than women following exposure to attractive opposite-sex primes than following exposure to unattractive opposite-sex primes.

\subsection{Method}

\subsubsection{Participants}

One hundred and thirty-three students from a college in the north of Israel (mean age $24.51, \mathrm{SD}=2.50$ ) participated in the study. Sixty-seven of the participants were female (mean age $24.60, \mathrm{SD}=2.52$ ), and 66 were male (mean age $24.42, \mathrm{SD}=2.50)$. Participants were recruited through advertisements at the college and did not receive compensation for their participation. They were prescreened for sexual orientation. Only heterosexual students participated in the study. 


\subsubsection{Materials and Procedure}

The study was approved by the institutional ethical review boards (IRBs) of the Yezreel Valley College. After giving their fully informed consent, participants were tested individually in a small room, with only a computer provided on a desk, and no other distracting stimuli. After completing a background questionnaire (e.g., sex, age), participants were instructed to fixate on a cross that appeared in the middle of the screen for $350 \mathrm{~ms}$. Next, they participated in consecutive priming sessions-the first presenting neutral primes and the second and third sessions either attractive or unattractive primes-followed by a task phase.

Primes. In the first priming session, participants were exposed to four neutral stimuli (e.g., a photo of a table) in order to mask potential environmental stimuli (e.g., pre-exposure to males or females in the lab) from remaining active; they were then exposed to four photos of the opposite sex, either attractive or unattractive. The male photos had been previously rated by heterosexual female students, and the female pictures by heterosexual male students, as extremely attractive or unattractive. Each photo was presented for $30 \mathrm{~ms}$. The order of the prime sessions was counterbalanced, with half the participants exposed first to the attractive and then to the unattractive session, and vice versa. Humor task. Similarly to the procedure described by Greengross and Miller (2011), Participants were shown two pictures (one each in the second and third prime sessions) without a caption. For each of the two uncaptioned pictures, participants were asked to write a funny caption within a limited time frame $(40 \mathrm{sec})$. The pictures had been previously rated by five male and five female students as funny in comparison to eight different pictures presented to them. The order in which the pictures were presented was counterbalanced as well. Subsequently, three judges (two men and one woman) blindly rated every caption on a scale from 1 ("not funny at all") to 7 ("very funny"). Internal reliability (Cronbach's alpha) was .73 following the unattractive primes and .59 following the attractive primes, consistent with former studies (Feingold \& Mazzella, 1993; Masten, 1986), but relatively lower than in Greengross and Miller's (2011) study. Judges' ratings were averaged to form two scores per participant (one for humor production following the unattractive priming and one for humor production following the attractive priming). A manipulation check included two questions presented to participants, whether they knew what the purpose of the experiment was and whether they noticed what primes were used in the study. None of the participants were aware of the purpose of the experiment or the nature of the priming stimuli.

\subsection{Results}

Sex differences. To examine sex differences in the overall humor production score, I conducted an independent sample $t$-test with sex as the independent variable and the humor score as the dependent variable. No sex difference was found $[t(131)=.78, p=.439$; Cohen's $d=.13]$. 
Attraction primes. To examine the attraction priming effect in the overall humor production score, I conducted paired sample $t$-tests with attraction as a within-participant independent variable and humor score as the dependent variable. No difference was found in humor production after exposure to attractive vs. unattractive priming $[t(132)=.39, p=.701$; Cohen's $d=.03]$.

Sex and attraction primes. The main hypothesis predicted an interaction between sex and attractiveness priming on humor production, with men showing humor enhancement following exposure to attractive women, and women not showing such enhancement. The hypothesis was tested using a mixed ANOVA, with attraction primes as the within-participant and sex as the between-participants independent variables, and humor score as the dependent variable. The order of the attractive vs. non-attractive primes and the order of picture presentation were also included in the model as between-participants variables. No main effects of the order of attraction primes or of picture presentation were found ( $p$ s $>.05$ ), and no significant interaction was found between sex and attraction priming $\left[F(1,131)=.75, p=.387 ; \eta_{p}^{2}=.01\right]$.

\subsection{Discussion}

The findings did not support any of the hypotheses of the preliminary study. Men did not show higher humor production than women, in contrast to the findings of earlier studies, suggesting that men show better humor ability than women. For example, Greengross and Miller (2011) documented higher average humor ability in men. In their study, men and women were asked to produce as many captions as they could to a given cartoon. Men produced more captions than women, and their captions were rated on average as funnier than those of women. The authors argued that their findings were consistent with the sexual signaling hypothesis, which holds that humor has evolved as a signal of mate quality and therefore men signal intelligence through humor. In their study, Greengross and Miller asked participants to produce several captions per cartoon, and for each participant the highest rated caption was chosen to represent the participant's humor ability. In the present study, participants were asked to produce only one caption per picture. The averaged humor scores were low, and on average participants failed to produce funny captions. This is consistent with Greengross and Miller's finding that most captions in their study were rated low.

It is possible that humor is too complex to produce in a "one-shot trial", without supportive boosters. In the preliminary study, such supportive boosters were assumed to be the mating cues with which participants were primed. The hypothesis that exposure to attractive women would activate the female mate preferences in men, which in turn would be manifested in cognitive resources being channeled into the task of humor enhancement, was not supported by the findings. It is possible that simply viewing attractive women was not sufficient to activate the stored female mate preferences in men. Baker and Maner (2008) found that the relationship between physical attractiveness cues and elevated risk 
taking in men is sensitive to one's motivational state. Men who simply viewed attractive women did not take more risks, except when their interest in procuring a mate was present.

\section{Study 2}

Study 2 tested the same hypotheses of the preliminary study, using a longer presentation duration of primes-100 ms-which is believed to lie on the threshold between a suboptimal and fully optimal presentation (Phaf et al., 2005). The preliminary study manipulation check revealed that participants were unaware of the nature of the priming stimuli. Perhaps a mere presentation of mating cues would activate the stored representation of female mate preferences in memory in men (Roney, 2003). Furthermore, this experiment added the situational factor of intrasexual competition. Since humor ability is associated with other qualities that are highly valued by women, intrasexual competition may result in higher humor ability in men, but not in women. Therefore, I hypothesized that in general men would show higher humor production ability than women under conditions of intrasexual competition. Secondly, I hypothesized that mating goals could be activated in men by pairing two substantial cues: exposure to attractive women and the presence of a potential male rival. I expected this pairing to produce a cumulative effect in activating the need for men to display their assets, which in turn would translate into a higher display of humor ability. The hypotheses of Study 2 were as follows:

1) Men will exhibit higher humor production than women.

2) With exposure to intrasexual competition, men will exhibit higher humor production than women, whereas without exposure to intrasexual competition, they will exhibit higher humor production than women, but to a lesser extent.

3) With exposure to intrasexual competition, men will show greater humor enhancement following exposure to attractive opposite-sex primes as opposed to exposure to unattractive opposite-sex primes, than will women, whereas without exposure to intrasexual competition men and women will not differ in humor enhancement following exposure to attractive opposite-sex primes as opposed to exposure to unattractive opposite-sex primes.

\subsection{Method}

\subsubsection{Participants}

One-hundred and seventy-three students from a college in the north of Israel (mean age $24.71, \mathrm{SD}=3.44$ ) participated in the study: 87 women (mean age $24.21, \mathrm{SD}=3.49$ ) and 86 men (mean age 25.21, SD =3.34). Participants were recruited through advertisements at the college and did not receive compensation for their participation. They were prescreened for sexual orientation. Only heterosexual students participated in the study.

\subsubsection{Materials and Procedure}

The design and all the materials were similar to the preliminary study, except for 
two differences: 1) each photo in the attractive vs. unattractive primes was presented for $100 \mathrm{~ms}$; 2) half of the participants were tested in same-sex pairs in a small room with only two computers, one on each desk, $200 \mathrm{~cm}$ apart from each other. The members of the pair were introduced to each other by the experimenter as both participating in this research and were instructed not to communicate or to have any eye contact with each other during the experimental session (the experimenter verified that the two participants were not previously acquainted). Subsequently, three judges (two men and one woman) blindly rated every caption on a scale from 1 ("not funny at all") to 7 ("very funny"). Internal reliability (Cronbach's alpha) following the unattractive primes was .63 on average, and .66 following the attractive primes. Judges' ratings were averaged to form two scores per participant (one for humor production following the unattractive priming and one for humor production following the attractive priming). A manipulation check included two questions presented to participants: whether they knew what the purpose of the experiment was and whether they noticed what primes were used in the study. All participants acknowledged that they saw the photos, but none was aware of the purpose of the experiment or the connection between the nature of primes and the humor task.

\subsection{Results}

Sex differences. To examine sex differences in the overall humor production score, I conducted an independent sample $t$-test with sex as the independent variable and the humor score as the dependent variable. The results indicated a sex difference $[t(171)=6.60, p=.000$; Cohen's $d=1.01]$, with men showing higher humor ability $(M=2.95, \mathrm{SD}=1.02)$ than women $(M=2.07, \mathrm{SD}=.69)$.

Intrasexual competition and sex. The second hypothesis predicted an interaction between sex and intrasexual competition on humor production, with men showing higher humor production with an intrasexual competition cue, whereas without an intrasexual cue, sex differences are demonstrated but to a lesser extent. I tested the hypothesis using a two-way ANOVA, with sex and intrasexual competition as the between-participants independent variables, and humor score as the dependent variable. The order of the picture presentation was also included in the model as between-participants variable. No main effect or interaction with other independent variables was found ( $p s>.05)$; therefore this variable was dropped from subsequent analysis. A significant interaction between sex and intrasexual competition was found $\left[F(1,169)=51.04, p=.000 ; \eta_{p}^{2}\right.$ $=.23]$. To examine sex differences in the overall humor production score separately for each group (exposed/not exposed) to intrasexual competition, I conducted two independent sample $t$-tests with sex as the independent variable and the humor score as the dependent variable. For the group exposed to the intrasexual competition cue, the results indicated a sex difference $[t(80)=8.85, p$ $=.000$; Cohen's $d=1.96$, with men showing higher humor ability $(M=3.73, \mathrm{SD}$ $=.89)$ than women $(M=2.03, \mathrm{SD}=.84)$. In contrast, for the group not exposed 
to the intrasexual competition cue, no sex difference was found $[t(89)=1.43, p$ $=.156$; Cohen's $d=.31]$.

Intrasexual competition, sex, and attraction primes. The third hypothesis predicted an interaction between intrasexual competition cue, sex and attraction priming on humor production, with men showing humor enhancement following exposure to attractive women, and women not showing such enhancement, when both are primed with an intrasexual competition cue. No sex differences are expected when women and men are not exposed to an intrasexual competition cue. I tested this hypothesis using a mixed ANOVA, with attractiveness priming as the within-participant and sex and intrasexual competition cue as the between-participants independent variables, and humor score as the dependent variable. The order of the attractiveness primes and the order of the picture presentation were also included in the model as between-participants variables. No main effects or interaction with other independent variables were found ( $p$ s $>.05$ ), therefore, these variables were dropped from subsequent analysis. A marginally significant interaction between intrasexual competition cue, sex and attraction prime was found $\left[F(1,169)=3.59, p=.060 ; \eta_{p}^{2}=.02\right]$. Further analyses revealed that this three-way interaction was due to the presence of a significant sex $\mathrm{X}$ attraction prime interaction for the intrasexual competition cue $[F$ $(1,80)=4.93, p=.029 ; \eta_{p}^{2}=.06$, see Figure 1]. The difference between humor production following unattractive vs. attractive primes was not significant for women $[t(41)=.46, p=.647]$, but reached significance for men $[t(39)=2.33, p$ $=.025]$. Men showed humor enhancement after exposure to attractive women $(M=4.06, \mathrm{SD}=1.28)$ as opposed to exposure to unattractive ones $(M=3.39, \mathrm{SD}$ $=1.25)$. No significant interaction was found between sex and attraction priming $\left[F(1,89)=.01, p=.933 ; \eta_{p}^{2}=.00\right.$, see Figure 2$]$ for the group not exposed to intrasexual competition cue.

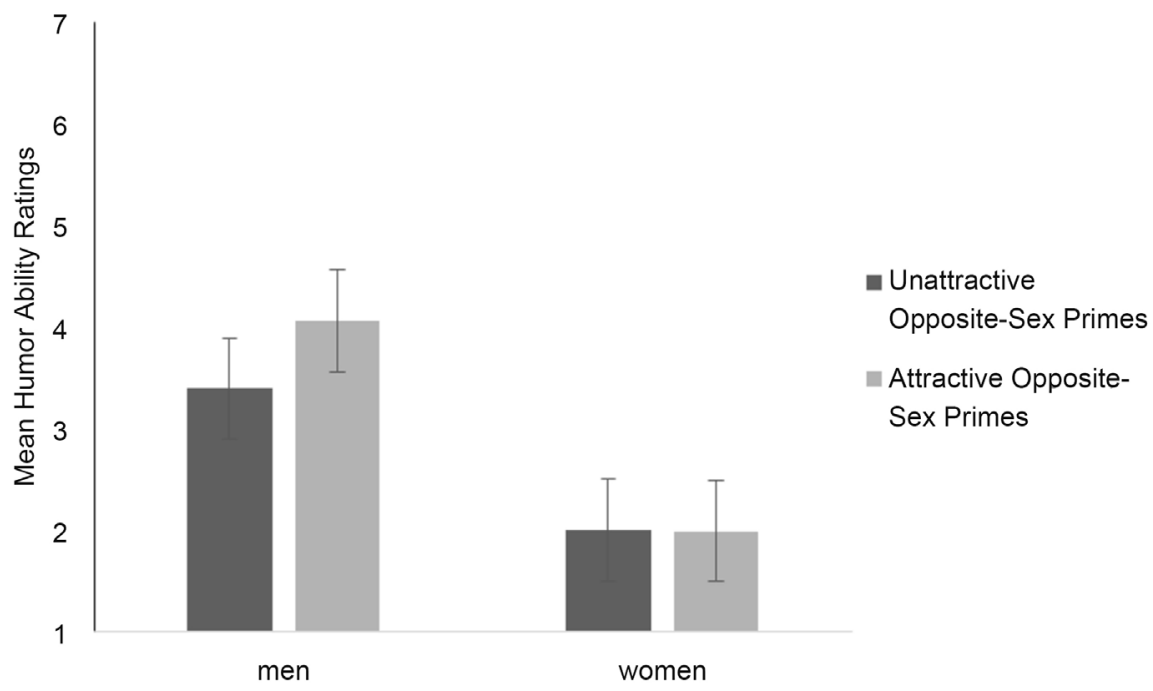

Figure 1. Mean humor ability ratings $( \pm S E)$ of men and women following exposure to unattractive and attractive opposite-sex primes (100 ms), facing intrasexual competition. 


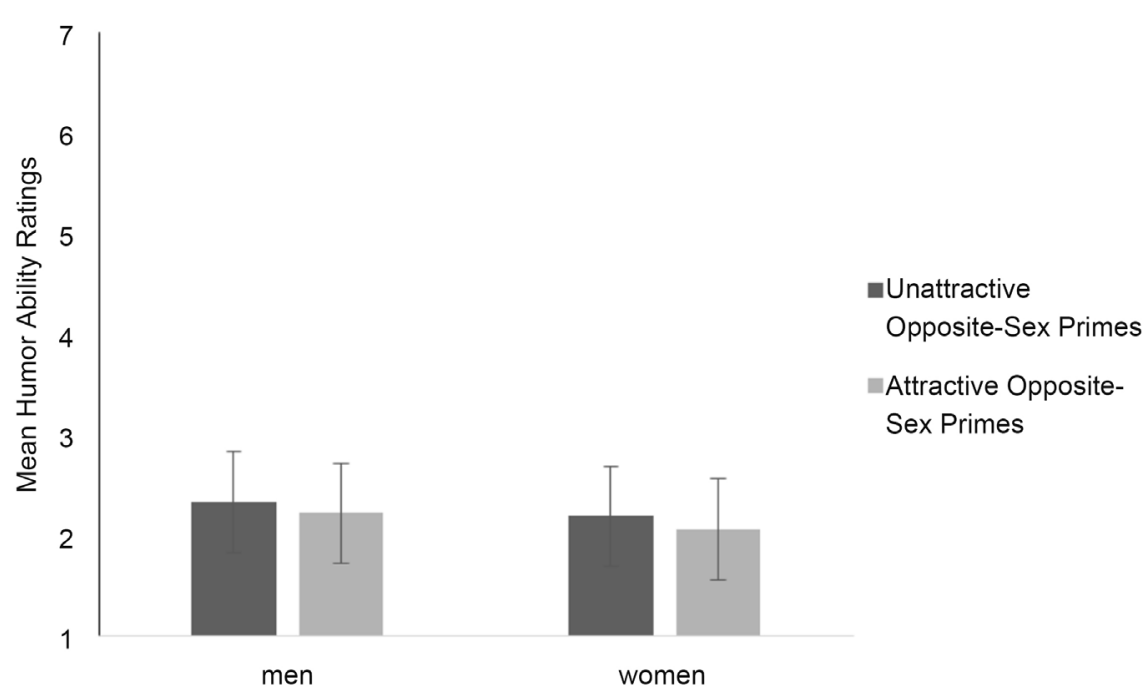

Figure 2. Mean humor ability ratings $( \pm S E)$ of men and women following exposure to unattractive and attractive opposite-sex primes (100 ms).

\subsection{Discussion}

In Study 2, the findings support the hypotheses. Men showed higher levels of humor ability than did women in general; however further analyses showed that the source of this effect was due to the exposure to intrasexual competition and following exposure to attractive opposite-sex primes in particular. Study 2 was designed, in part, to make more favorable the conditions under which mating cues prime changes in humor production in men. Given that subliminal exposure to attractive women did not activate the female mate preference in men in the preliminary study, Study 2 included supraliminal priming to enable the conscious processing of stimuli. Nevertheless, lengthening the presentation duration of primes did not produce sex differences in humor production nor the predicted humor enhancement in men following exposure to attractive women pictures. Another aim of the present study was to examine the influence of intrasexual competition on humor production. The presence of the same-sex participant was designed to serve as a situational cue signaling potential intrasexual competition. Men, but not women, experienced the same-sex participant as a potential rival, which in turn led them to accentuate their assets corresponding to female mate preferences; in this case, humor ability. The evolutionary cognitive framework holds that, as a result of different fitness pressures, women have developed preferences for social status, financial resources, and intelligence (Buss, 1989; Buss, 2003; Shackelford et al., 2005). Earlier studies have established that humor production ability is a prominent indicator of intelligence (e.g., Feingold \& Mazzella, 1991; Greengross \& Miller, 2011; Howrigan \& MacDonald, 2008). Therefore, the task in the present study, which demanded humor production ability, was aligned with female mate preferences, but not with male mate preferences. Exposed to intrasexual competition, men but not women accepted the challenge of wittiness and provided funnier captions to the stimuli (when 
primed with either attractive or unattractive women). Men performed even better after being exposed to attractive women. The addition of another mating cue had a cumulative effect on men.

\section{General Discussion}

The present research examined whether the exposure to different mating cues enhances humor ability in men and women. As predicted, the results of Study 2 suggest that men, when primed with intrasexual competition, show higher humor ability than women, and when primed with intrasexual competition coupled with attractive opposite-sex primes, they show enhanced humor ability compared to their performance following exposure to unattractive opposite-sex primes. This is consistent with the three premises of the evolutionary cognitive framework: 1) that sexual selection pressures guide sex-differentiated mate processes, leading men and women to display assets, virtues, and traits-including mental abilities—valued by the other sex (Greengross \& Miller, 2011); 2) differential parental investment leads to sex-differentiated intrasexual competition, both in degree and in form (Trivers, 1972); and 3) emerging research in evolutionary psychology suggests that activating mating cues can facilitate cognitions and behaviors aimed at attracting a mate (Roney, 2003; Wilson \& Daly, 2004). The present study addressed the third premise, exploring the cues that serve to activate humor production in men and women. The results of the preliminary study did not support this premise. However, with the inclusion of a central cue, intrasexual competition, Study 2 confirmed the predicted enhancement in humor. This finding suggests that men store a representation of female mate preferences in memory (Roney, 2003). The activation process of these stored representations, leading to higher humor ability, manifests in the presence of intrasexual competition primes and is further enhanced by such mating cues as attractive women primes. These findings provide additional evidence of a cognitive model of mate attraction in which the cumulative exposure to cues may activate cognitive schemes of mate preferences that lead to modifications in mate attraction cognitions and behavior (Roney, 2003). Furthermore, the present findings support recent evidence indicating that intrasexual competition in men may play a larger role than female mate choice (Hill, Bailey, \& Puts, 2017; Kordsmeyer, Hunt, Puts, Ostner, \& Penke, 2018). For example, Kordsmeyer and colleagues (2018) found that physical dominance, but not sexual attractiveness, predicated mating success. The authors suggested that traits such as intelligence and humor may influence status, and in turn, mating success. Furthermore, the authors postulated that intrasexual competition and female mate choice may act in concert, as was demonstrated by the present findings. A word of caution is in order, given the small number of participants exposed to an intrasexual competition cue in Study 2. Although the mean difference between men and women did reach significance, as did the interaction of sex with the priming condition, these findings call for further replication. 
The results of the two studies reveal that on average, women maintained their performance on humor production across all four conditions: exposure to attractive vs. unattractive men, and exposure to intrasexual competition vs. the absence of such exposure. Women's humor ability was relatively low, which is consistent with previous evidence (Greengross \& Miller, 2011). As predicted, the exposure to attractive men did not serve as a mating cue for women, nor did the intrasexual competition cue. It appears that women did not experience the presence of the same-sex participant as a potential rival, even after exposure to attractive men. These results are consistent with sexual selection predictions regarding sex-differentiated mate preferences, given that the quality evaluated in the present study (humor ability) was associated with women's but not men's mate preferences (Brewer, 2017; Campbell, 2013; Fisher \& Fernández, 2017).

The current studies used the priming technique, which has been suggested as useful for evolutionary psychology research. One of the premises of the evolutionary cognitive framework is that mechanisms have evolved to activate behavior through unconscious processes (Millar \& Ostlund, 2006). In none of the studies were there indications that participants were aware of the nature of the manipulation. In the preliminary study, participants were exposed subliminally to photographs of the opposite sex based on the assumption that attractiveness may have evolved to the point where it is perceived even below the levels of conscious awareness (Massar \& Buunk, 2010). It was hypothesized that primes of attractive women would activate the stored female mate preferences in men, causing them to display higher humor ability, but the results of the preliminary study did not support this hypothesis. Study 2, which used the supraliminal presentation duration of primes, considered as the lower threshold of conscious processing, also did not yield significant results for the group not exposed to intrasexual competition. In contrast, in Study 2, combining exposure to attractive women with intrasexual competition activated the stored female mate preferences in men, resulting in an enhancement in humor ability. Since the duration of priming used in Study 2 involved exposure within the threshold of conscious processing, the influence of pairing cues (attractive opposite-sex photographs and the presence of a same-sex participant), should be examined using a combination of subliminal priming and intrasexual competition. This would make it possible to test assumptions based on the evolutionary framework regarding the unconscious infrastructure in human mating processes.

Humor production ability is assumed to be the most complex cognitive function of humans (Polimeni \& Reiss, 2006). The results of the two studies show that exposure to an attractive opposite-sex photograph was not a sufficient activating booster to the production of humor under forced condition. The findings of Study 2 emphasize the central role that intrasexual competition plays in humor production: experiencing the presence of a potential rival led men, but not women, to display substantially higher humor ability than they did in the absence of intrasexual competition. Future studies should examine other cognitive 
abilities (e.g., insight problem solving, rational vs. irrational decision making) and the combination of cues that trigger their activation to portray in more detail the contours of female mate preferences and their activating mechanisms in men.

\section{Conflicts of Interest}

The author declares no conflicts of interest regarding the publication of this paper.

\section{References}

Alexander, R. D. (1986). Ostracism and Indirect Reciprocity: The Reproductive Significance of Humor. Ethology and Sociobiology, 7, 253-270. https://doi.org/10.1016/0162-3095(86)90052-X

Arden, R., Gottfredson, L. S., \& Miller, G. (2009). Does a Fitness Factor Contribute to the Association between Intelligence and Health Outcomes? Evidence from Medical Abnormality Counts among 3654 US Veterans. Intelligence, 37, 581-591. https://doi.org/10.1016/j.intell.2009.03.008

Baker, M., \& Maner, J. K. (2008). Risk-Taking as a Situationally Sensitive Male Mating Strategy. Evolution and Human Behavior, 29, 391-395. https://doi.org/10.1016/j.evolhumbehav.2008.06.001

Bressler, E. R., \& Balshine, S. (2006). The Influence of Humor on Desirability. Evolution and Human Behavior, 27, 29-39. https://doi.org/10.1016/j.evolhumbehav.2005.06.002

Bressler, E. R., Martin, R. A., \& Balshine, S. (2006). Production and Appreciation of Humor as Sexually Selected Traits. Evolution and Human Behavior, 27, 121-130. https://doi.org/10.1016/j.evolhumbehav.2005.09.001

Brewer, G. (2017). Single and Partnered Women: Competing to Obtain and Retain High-Quality Men. In M. L. Fisher (Ed.), The Oxford Handbook of Women and Competition (pp. 301-317). New York: Oxford University Press.

Buss, D. M. (1988). The Evolution of Human Intrasexual Competition: Tactics of Mate Attraction. Journal of Personality and Social Psychology, 54, 616-628. https://doi.org/10.1037/0022-3514.54.4.616

Buss, D. M. (1989). Sex Differences in Human Mate Preferences: Evolutionary Hypotheses Tested in 37 Cultures. Behavioral and Brain Sciences, 12, 1-49. https://doi.org/10.1017/S0140525X00023992

Buss, D. M. (2003). The Evolution of Desire (Revision ed.). New York: Basic Books.

Buss, D. M., \& Dedden, L. A. (1990). Derogation of Competitors. Journal of Social and Personal Relationships, 7, 395-422. https://doi.org/10.1177/0265407590073006

Campbell, A. (2013). A Mind of Her Own: The Evolutionary Psychology of Women (2nd ed.). Oxford: Oxford University Press. https://doi.org/10.1093/acprof:oso/9780199609543.001.0001

Chang, Y-T., Ku, L-C., \& Chen, H-C. (2018). Sex Differences in Humor Processing: An Event-Related Potential Study. Brain and Cognition, 120, 34-42. https://doi.org/10.1016/j.bandc.2017.11.002

Clutton-Brock, T. H., \& Vincent, A. C. J. (1991). Sexual Selection and the Potential Reproductive Rates of Males and Females. Nature, 351, 58-60. https://doi.org/10.1038/351058a0 
Darwin, C. (1871). The Descent of Man and Selection in Relation to Sex. London: Murray.

Dawkins, R. (2004). The Ancestor's Tale. London: Weidenfeld and Nicolson.

De Waal, F. (1982). Chimpanzee Politics: Power and Sex among Apes. New York: Harper and Row.

Feingold, A., \& Mazzella, R. (1991). Psychometric Intelligence and Verbal Humor Ability. Personality \& Individual Differences, 12, 427-435. https://doi.org/10.1016/0191-8869(91)90060-O

Feingold, A., \& Mazzella, R. (1993). Preliminary Validation of a Multidimensional Model of Wittiness. Journal of Personality, 61, 439-456. https://doi.org/10.1111/j.1467-6494.1993.tb00288.x

Fisher, M. L., \& Fernández, A. M. (2017). The Influence of Women's Mate Value on Intrasexual Competition. In M. L. Fisher (Ed.), The Oxford Handbook of Women and Competition (pp. 281-299). New York: Oxford University Press. https://doi.org/10.1093/oxfordhb/9780199376377.013.52

Geary, D. C. (2000). Evolution and Proximate Expression of Human Paternal Investment. Psychological Review, 126, 55-77.

Greengross, G., \& Miller, G. (2011). Humor Ability Reveals Intelligence, Predicts Mating Success, and Is Higher in Males. Intelligence, 39, 188-192.

https://doi.org/10.1016/j.intell.2011.03.006

Griskevicius, V., Cialdini, R. B., \& Kenrick, D. T. (2006). Peacocks, Picasso, and Parental Investment: The Effects of Romantic Motives on Creativity. Journal of Personality and Social Psychology, 91, 63-76. https://doi.org/10.1037/0022-3514.91.1.63

Hill, A. K., Bailey, D. H., \& Puts, D. A. (2017). Gorillas in Our Midst? Human Sexual Dimorphism and Contest Competition in Men. In M. Tibayrenc, \& F. J. Ayala (Eds.), On Human Nature: Biology, Psychology, Ethics, Politics, and Religion (pp. 235-249). New York: Academic Press.

Hone, L. S. E., Hurwitz, W., \& Lieberman, D. (2015). Sex Differences in Preferences for Humor: A Replication, Modification, and Extension. Evolutionary Psychology, 13, 167-181. https://doi.org/10.1177/147470491501300110

Howrigan, D. P., \& MacDonald, K. B. (2008). Humor as a Mental Fitness Indicator. Evolutionary Psychology, 6, 652-666. https://doi.org/10.1177/147470490800600411

Jung, W. E. (2003). The Inner Eye Theory of Laughter: Mindreader Signals Cooperator Value. Evolutionary Psychology, 1, 214-253. https://doi.org/10.1177/147470490300100118

Kanazawa, S. (2000). Scientific Discoveries as Cultural Displays: A Further Test of Miller's Courtship Model. Evolution and Human Behavior, 21, 317-321. https://doi.org/10.1016/S1090-5138(00)00051-9

Kordsmeyer, T. L., Hunt, J., Puts, D. A., Ostner, J., \& Penke, L. (2018). The Relative Importance of Intra- and Intersexual Selection on Human Male Sexually Dimorphic Traits. Evolution \& Human Behavior, 1-13.

Lundy, D. E., Tan, J., \& Cunningham, M. R. (1998). Heterosexual Romantic Preferences: The Importance of Humor and Physical Attractiveness for Different Types of Relationships. Personal Relationships, 5, 311-325. https://doi.org/10.1111/j.1475-6811.1998.tb00174.x

Martin, R. A. (2007). The Psychology of Humor: An Integrated Approach. Burlington: Elsevier Academic Press.

Massar, K., \& Buunk, A. P. (2010). Judging a Book by Its Cover: Jealousy after Subliminal 
Priming with Attractive and Unattractive Faces. Personality and Individual Differences, 49, 634-638. https://doi.org/10.1016/j.paid.2010.05.037

Masten, A. S. (1986). Humor and Competence in School-Aged Children. Child Development, 57, 461-473.

Millar, M. G., \& Ostlund, N. M. (2006). The Effects of a Parenting Prime on Sex Differences in Mate Selection Criteria. Personality and Social Psychology Bulletin, 32, 1459-1468. https://doi.org/10.1177/0146167206291340

Miller, G. F. (1999). Sexual Selection for Cultural Displays. In R. Dunbar, C. Knight, \& C. Power (Eds.), The Evolution of Culture: An Interdisciplinary View (pp. 71-91). Edinburgh: Edinburgh University Press.

Miller, G. F. (2000). Sexual Selection for Indicators of Intelligence. In G. Bock, J. Goode, \& K. Webb (Eds.), The Nature of Intelligence (pp. 260-275). Novartis Foundation Symposium 233. Chichester: Wiley.

Miller, G. F. (2001). Aesthetic Fitness: How Sexual Selection Shaped Artistic Virtuosity as a Fitness Indicator and Aesthetic Preferences as Mate Choice Criteria. Bulletin of Psychology and the Arts, 2, 20-25.

Morier, D., \& Seroy, C. (1994). The Effect of Interpersonal Expectancies on Men's Self-Presentation of Gender Role Attitudes to Women. Sex Roles, 31, 493-504. https://doi.org/10.1007/BF01544203

Phaf, R. H., Wendte, R., \& Rotteveel, M. (2005). Privileged Processing of Low Spatial Frequencies in Emotional Faces? In B. G. Bara, L. Barsalou, \& M. Bucciarelli (Eds.), Proceedings of the XXVII Annual Conference of the Cognitive Science Society (pp. 1744-1749). Austin, TX: Cognitive Science Society.

Polimeni, J., \& Reiss, J. P. (2006). The First Joke: Exploring the Evolutionary Origins of Humor. Evolutionary Psychology, 4, 347-366. https://doi.org/10.1177/147470490600400129

Reay, M. (2015). Using "Wild” Laughter to Explore the Social Sources of Humor. Social Forces, 93, 1241-1265. https://doi.org/10.1093/sf/sou106

Roney, J. R. (2003). Effects of Visual Exposure to the Opposite Sex: Cognitive Aspects of Mate Attraction in Human Males. Personality and Social Psychology Bulletin, 29, 393-404. https://doi.org/10.1177/0146167202250221

Shackelford, T. K., Schmitt, D. P., \& Buss, D. M. (2005). Universal Dimensions of Human Mate Preferences. Personality and Individual Differences, 39, 447-458. https://doi.org/10.1016/j.paid.2005.01.023

Trivers, R. L. (1972). Parental Investment and Sexual Selection. In B. Campbell (Ed.), Sexual Selection and the Descent of Man (pp. 136-179). Chicago: Aldine.

Walters, S., \& Crawford, C. B. (1994). The Importance of Mate Attraction for Intrasexual Competition in Men and Women. Ethology and Sociobiology, 15, 5-30. https://doi.org/10.1016/0162-3095(94)90025-6

Wilson, M., \& Daly, M. (2004). Do Pretty Women Inspire Men to Discount the Future? Proceedings of the Royal Society of London Series B, 271, S177-S179.

Yong, J. C., \& Li, N. P. (2012). Cash in Hand, Want Better Looking Mate: Significant Resource Cues Raise Men's Mating Standards. Personality and Individual Differences, 53, 55-58. https://doi.org/10.1016/j.paid.2012.02.018

Zanna, M. P., \& Pack, S. J. (1975). On the Self-Fulfilling Nature of Apparent Sex Differences in Behavior. Journal of Experimental Social Psychology, 11, 583-591.

https://doi.org/10.1016/0022-1031(75)90009-8 